\title{
Response to: Remote Diabetic Foot Temperature Monitoring for Early Detection of Diabetic Foot Ulcers: A Cost-Effectiveness Analysis [Letter]
}

\author{
Jaap J van Netten', Marcel GW Dijkgraaf', Sicco A Bus'
}

\begin{abstract}
'Amsterdam UMC, University of Amsterdam, Department of Rehabilitation Medicine, Amsterdam Movement Sciences, Amsterdam, the Netherlands; ${ }^{2}$ Amsterdam UMC, University of Amsterdam, Department of Epidemiology and Data Science, Amsterdam, the Netherlands

Correspondence: Jaap J van Netten, Email j.j.vannetten@amsterdamumc.nl
\end{abstract}

\section{Dear editor}

We read with pleasure the recent article in your journal on the cost-effectiveness of remote diabetic foot temperature monitoring by Brooks et al. ${ }^{1}$ Diabetic foot ulcers pose a major healthcare burden, and insight into cost-effectiveness of treatments in this field is scarce, especially in preventing foot ulcers. ${ }^{2}$ Studies with original data are clearly preferred to inform clinicians, researchers and policy-makers on the potential cost-savings and health gains of preventative interventions. But modelling analyses such as by Brooks et al can provide relevant insights.

For modelling analyses to be meaningful, assumptions must be based on both published evidence and clinical reasoning, and must be reasonable and logical. For a cost-effectiveness analysis on remote foot temperature monitoring, two assumptions are key: the potential effectiveness of the intervention, ie the number or percentage of (recurrent) ulcers prevented, and the treatment costs of one ulcer. Unfortunately, both assumptions made by Brooks et al are skewed towards finding positive outcomes on the intervention.

Regarding the potential effectiveness, the authors set the probability of ulcer recurrence in standard care at $40 \%$, in line with current literature. However, an expected $19 \%$ re-ulceration in people who remotely monitor their temperature suggests a potential effect size $>50 \%$. While this aligns with data from studies from the 2000 s, the two recent trials on this topic both show effect sizes around 25\%. ${ }^{3,4}$ Further, recurrence rate estimates made by Brooks et al ${ }^{1}$ for people nonadherent to temperature monitoring were similar to standard care (i.e. $40 \%$ ), while these are likely higher, as nonadherence to temperature monitoring will be associated with general non-adherence to preventative treatment. As such, the assumptions made in the study by Brooks et $\mathrm{al}^{1}$ are probably overestimations of the potential effectiveness of temperature monitoring.

Regarding the costs of ulcer treatment, an estimated 13 months average healing time for each ulcer is used, based on a paper that is almost 20 years old. This is an overestimation of costs for ulcer treatment, as it suggests an average $>30,000$ USD for each ulcer that develops. Recent studies consistently show average ulcer costs around 10,000 USD. ${ }^{5}$ Further, numerous observational cohort studies show median time to healing around 3 months, and one-year healing rates above $70 \%$, indicating that 13 months average healing time is not reflecting current standard care. The restriction (in this letter) of five references and absence of a systematic review on this topic refrains us from referring to these studies. We are happy to provide these upon request.

Taken together, this means that the effectiveness of remote temperature monitoring is likely half as good as the authors modelled, while the costs related to each ulcer prevented are likely three times lower. For cost-effectiveness analyses, that suggests a six-fold reduction of potential effects, and a high likelihood that a device costing 1500 USD is not cost-effective. 
An upcoming cost-effectiveness study using empirical data based on our $\mathrm{RCT}^{4}$ is forthcoming. Awaiting these results, modelling studies are needed, but should make realistic assumptions based on recent evidence, and should include sensitivity analyses with ranges of (realistic) assumptions.

\section{Disclosure}

The authors report no conflicts of interest in this communication.

\section{References}

1. Brooks E, Burns M, Ma R, Scholten HJ, Becker S. Remote diabetic foot temperature monitoring for early detection of diabetic foot ulcers: a costeffectiveness analysis. Clinicoecon Outcomes Res. 2021;13:873-881. doi:10.2147/CEOR.S322424

2. Bus SA, Lavery LA, Monteiro-Soares M, et al. Guidelines on the prevention of foot ulcers in persons with diabetes (IWGDF 2019 update). Diabetes Metab Res Rev. 2020;36(Suppl 1):e3269. doi:10.1002/dmrr.3269

3. Alahakoon C, Fernando M, Galappaththy C, et al. Meta-analyses of randomized controlled trials reporting the effect of home foot temperature monitoring, patient education or offloading footwear on the incidence of diabetes-related foot ulcers. Diabet Med. 2020;37(8):1266-1279. doi:10.1111/dme.14323

4. Bus SA, Aan de Stegge WB, van Baal JG, Busch-Westbroek TE, Nollet F, van Netten JJ. Effectiveness of at-home skin temperature monitoring in reducing the incidence of foot ulcer recurrence in people with diabetes: a multicenter randomized controlled trial (DIATEMP). BMJ Open Diabetes Res Care. 2021;9(1):e02392. doi:10.1136/bmjdrc-2021-002392

5. Petrakis I, Kyriopoulos IJ, Ginis A, Athanasakis K. Losing a foot versus losing a dollar; a systematic review of cost studies in diabetic foot complications. Expert Rev Pharmacoecon Outcomes Res. 2017;17(2):165-180. doi:10.1080/14737167.2017.1305891

Dove Medical Press encourages responsible, free and frank academic debate. The content of the ClinicoEconomics and Outcomes Research 'letters to the editor' section does not necessarily represent the views of Dove Medical Press, its officers, agents, employees, related entities or the ClinicoEconomics and Outcomes Research editors. While all reasonable steps have been taken to confirm the content of each letter, Dove Medical Press accepts no liability in respect of the content of any letter, nor is it responsible for the content and accuracy of any letter to the editor.

ClinicoEconomics and Outcomes Research

\section{Publish your work in this journal}

ClinicoEconomics and Outcomes Research is an international, peer-reviewed open-access journal focusing on Health Technology Assessment, Pharmacoeconomics and Outcomes Research in the areas of diagnosis, medical devices, and clinical, surgical and pharmacological intervention. The economic impact of health policy and health systems organization also constitute important areas of coverage. The manuscript management system is completely online and includes a very quick and fair peer-review system, which is all easy to use. Visit http://www.dovepress.com/testimonials.php to read real quotes from published authors.

Submit your manuscript here: https://www.dovepress.com/clinicoeconomics-and-outcomes-research-journal 